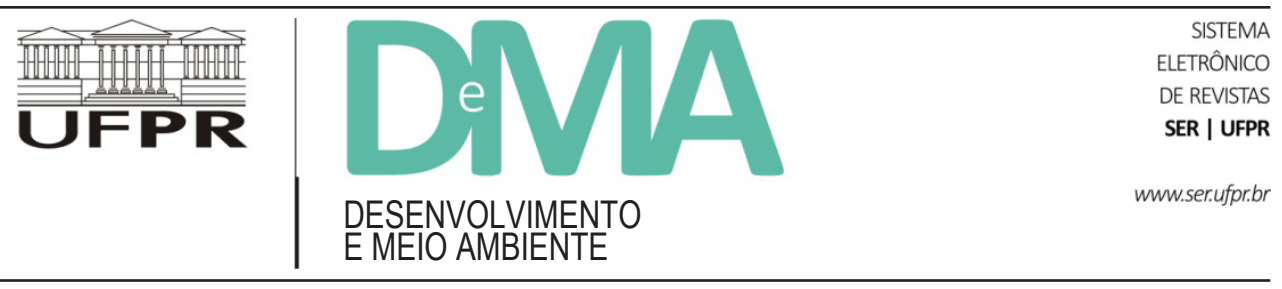

\title{
A mudança climática no enquadramento discursivo da revista Época
}

\section{Climate Change in the Discursive Framework of Época Magazine}

\author{
Cláudia Herte de MORAES ${ }^{1^{*}}$ \\ ${ }^{1}$ Departamento de Ciências da Comunicação, Universidade Federal de Santa Maria (UFSM), Frederico Westphalen, RS, Brasil. \\ *E-mail de contato: chmoraes@gmail.ufsm.br
}

Artigo recebido em 30 de outubro de 2016, versão final aceita em 14 de fevereiro de 2017.

RESUMO: O papel dos meios de comunicação está no centro da crise climática, pois são responsáveis pela difusão de informações em larga escala, indicando as escolhas de futuro à sociedade. A partir disso, o artigo discute o pensamento da sociologia ambiental em relação aos riscos, à modernidade reflexiva e ao saber ambiental, situando esses conceitos como base dos discursos que circulam socialmente. $\mathrm{O}$ artigo analisa uma reportagem especial da cobertura da Rio +20 realizada no Brasil pela revista Época, com objetivo de compreender de que forma o discurso sobre a mudança climática articula a noção de futuro (os caminhos a seguir) e, por consequência, a relação homem-natureza subjacente. Apoiado na Análise do Discurso a partir de Michel Pêcheux e das Teorias do Jornalismo construcionistas, indica o enquadramento discursivo como dispositivo de análise. A revista Época realizou seu enquadramento com ênfase na Economia Verde, a partir de um discurso hegemônico, porém, trouxe alguns elementos de fundo ecossocial. Dessa forma, identificou-se uma Formação Discursiva Ecotecnocrática com leve atravessamento da Formação Discursiva Ecossocial.

Palavras-chave: mudança climática; práticas jornalísticas;. Rio+20;. revista Época;. enquadramento discursivo.

ABSTRACT: The role of the media is at the center of the climate crisis, as they are responsible for the dissemination of information on a large scale, indicating future choices for society. From this, the article discusses scholarship in environmental sociology in relation to risks, reflexive modernity and environmental knowledge, locating these concepts at the basis of the discourses that circulate socially. The article analyzes a special news report from Época magazine on the coverage of Rio + 20, which was held in Brazil, in order to understand how the discourse on climate change articulates the notion of the future (possible pathways) and the underlying human-nature relationship. Based on Discourse Analysis as developed by Michel Pêcheux and on Constructivist Theories of Journalism, it uses the notion of discursive framework as an analytical device. Época magazine framed its discourse trough an emphasis on the Green Economy, a key notion from hegemonic discourses. However, it also presented some elements of eco-social background. Hence, an Eco-technocratic Discursive Formation was identified as dominant but "lightly" traversed by an Eco-social Discursive Formation.

Keywords: climate change; journalistic practices; Rio + 20; Época magazine; discursive framework. 


\section{Introdução}

A mudança climática pode ser considerada a maior crise ambiental de todos os tempos, especialmente por sua dimensão global. O ano de 2007 teve importância fundamental na difusão da questão e na sua projeção mundial, com a divulgação do IV Relatório do Painel Intergovernamental sobre Mudança do Clima (IPCC - sigla de Intergovernmental Panel on Climate Change), que apontou ser inequívoca a tese sobre o aquecimento global, obtendo ampla cobertura midiática no mundo (IPCC, 2007).

A crise ambiental climática é representada em forma de ameaça à sobrevivência e, portanto, ao futuro da humanidade por diferentes atores sociais, entre eles, especialmente: cientistas, que pesquisam os impactos do fenômeno sobre a produção de alimentos, biodiversidade, escassez de água, saúde populacional, entre outros fatores associados; e organismos internacionais, com destaque ao já citado IPCC, mas também a Organização das Nações Unidas para a Alimentação e a Agricultura $(F A O)$ e a Organização para a Educação, a Ciência e a Cultura das Nações Unidas (UNESCO), que frequentemente abastecem os noticiários ao redor do mundo.

A condição de ameaça e de risco acaba trazendo consigo uma série de debates na sociedade sobre como lidar com esta nova realidade, uma questão pública de proporções globais que esbarra no próprio entendimento do ser humano em sua relação com a natureza. Até que se tornasse uma questão ambiental a ser enfrentada, a mudança do clima teve acirrado debate no campo da ciência. Atualmente, no entanto, existe consenso entre os climatologistas sobre as principais teses do aquecimento global, havendo pontos de debate em aspectos específicos, tais como volume, intensidade e alcance de eventos extremos relacionados, e quanto às formas mais indicadas de mitigação e de adaptação. Há também um consenso em relação à ocorrência de ciclos de aquecimentos históricos, indicando-se, de forma majoritária, o papel das atividades humanas na ampliação desse fenômeno, na medida em que onera o sistema atmosférico com a grande emissão de gases e utiliza, de forma desenfreada, os bens naturais disponíveis.

Nos últimos anos, ocorreram eventos extremos que instauraram uma urgência para a tomada de posição em relação à crise climática. O papel dos meios de comunicação também está no centro dessa crise, já que é por meio de informações difundidas massivamente que a percepção da crise climática se constrói na sociedade.

As escolhas de futuro são baseadas em informações e representações sobre seus significados. Nesse contexto da comunicação ambiental, recortamos a questão do jornalismo como forma de produção do conhecimento, valorizado socialmente na sua tarefa de relatar discursos sobre os temas da atualidade. Em tese, o jornalismo deveria cuidar para que todos os pontos de vista envolvidos no tema viessem a público. No entanto, esse papel é pressionado por diferentes interesses envolvidos, especialmente do campo econômico e político, dos quais os meios tradicionais e hegemônicos socialmente emergem.

A problematização das escolhas, das mais simples às mais complexas, direciona o caminho a ser tomado nas negociações internacionais que buscam definir metas de redução de gases de efeito estufa. O mais recente e importante documento foi assinado por 195 países em 2015, na $21^{\text {a }}$ Conferência das Partes (COP21) da Convenção-Quadro das Nações Unidas sobre a Mudança do Clima (UNFCCC, sigla em Inglês), em Paris.

Com o Acordo de Paris, apresenta-se a necessidade de manutenção do aumento da temperatura 
média global em menos de $2{ }^{\circ} \mathrm{C}$ abaixo dos níveis pré-industriais, como forma de reduzir os riscos e impactos das alterações climáticas. $\mathrm{O}$ documento indica ainda que devem prosseguir os esforços para que o aumento da temperatura seja limitado em $1,5^{\circ} \mathrm{C}$.

Ao mesmo tempo em que há um conjunto de iniciativas preocupadas com o aquecimento global, oriundas de cientistas, sociedade civil, autoridades, empresas, organizações não governamentais e meios de comunicação, percebemos que o tema, por ser complexo e transversal, ainda carece de mais espaço e aprofundamento, no caso específico, em se tratando de jornalismo ambiental.

Com esse cenário, observamos a realização da Conferência das Nações Unidas sobre Desenvolvimento Sustentável $(\mathrm{Rio}+20$, em alusão à Conferência para o Meio Ambiente e o Desenvolvimento, a Eco92 ou Rio92) no Brasil, em 2012. As conferências da ONU são momentos importantes de visibilidade do tema ambiental, sendo a Rio92 considerada um marco na mobilização mundial. Para o Brasil, sediar novamente a Conferência era uma oportunidade única em se firmar globalmente como um país comprometido com o desenvolvimento sustentável. A temática definida para o evento foi "Economia verde, desenvolvimento sustentável e erradicação da pobreza".

A relação entre a Rio +20 e a mídia nacional deu-se entre críticas à capacidade de realização do governo brasileiro, à época comandado por Dilma Rousseff (PT), empenhado em apresentar projetos de sustentabilidade como vitrine internacional.

A escolha pela revista Época como objeto se justifica em função de este semanário estar vincu- lado a um grande conglomerado de comunicação, as Organizações Globo, com veículos de grande alcance de público e predomínio nos discursos hegemônicos no Brasil. ${ }^{1}$

Neste artigo, analisamos a reportagem especial da revista Época, edição 735, destacando os enquadramentos discursivos em relação à mudança do clima e às suas relações com o futuro. $\mathrm{O}$ objetivo é compreender como o discurso sobre a mudança climática articula a noção de futuro e, por consequência, a relação homem-natureza na publicação especial da revista, sendo objetos de análise: a capa, um conjunto de imagem e manchete ("Rio+20: O futuro dele depende de nós"); a chamada "O desafio de garantir riquezas e recursos para as próximas gerações"; e a reportagem de capa "Quanto vale o futuro", na mesma edição, que circulou em 18 de junho de 2012.

Com a perspectiva da Análise de Discurso a partir de Michel Pêcheux, o artigo está dividido em quatro partes, a partir desta introdução. Primeiramente, examinamos brevemente as bases do pensamento da sociologia ambiental em relação aos riscos, bem como a discussão sobre a racionalidade ambiental, importante para a percepção de novas possibilidades de encontro entre homens e natureza. Após, apresentamos o percurso metodológico, discutindo-se aspectos das Teorias do Jornalismo e da Análise do Discurso - AD e indicando o funcionamento do enquadramento discursivo, nosso dispositivo de análise. Nas considerações finais, ratificamos o debate em relação ao enquadramento discursivo sobre o tema da mudança do clima na reportagem da revista Época, durante a Rio +20 .

\footnotetext{
${ }^{1}$ A revista Época tem uma circulação média de 389 mil exemplares, segundo dados do Instituto Verificador de Circulação (IVC), no ano de 2012 (Malin, 2013). Apesar de não ser a mais antiga revista semanal do Brasil, tem seu valor atribuído de tradição por estar vinculada à Editora Globo e estar no mercado desde 1998.
} 


\section{Um futuro de riscos e incertezas}

Nesta seção, ao abordar os conceitos da Sociologia Ambiental, estamos organizando dois grupos de representações sobre o futuro e os caminhos a seguir diante da crise ecológica. O primeiro, de forma abrangente, é considerado antropocentrista, abrigando as correntes de modernização reflexiva, sociedade do risco e modernização ecológica, numa interpretação ecotecnocrática. O segundo grupo está voltado aos conceitos que visam à desconstrução desse lugar de fala, considerado hegemônico, sendo colocado com uma visão mais radical, a partir da ecologia profunda e do saber ambiental, ancorados numa interpretação ecossocial.

Segundo a visão do Iluminismo, o homem tem condições de moldar a história via racionalidade, buscando progressivamente mais conhecimento, sendo, dessa forma, capaz de controlar o futuro. O sentido de tal busca de ordenamento e estabilidade, no entanto, é cada vez mais questionado no mundo contemporâneo, pois este "não se parece muito com o que previram. Em vez de estar cada vez mais em nosso comando, parece um mundo em descontrole." (Giddens, 1999, p. 14). Mas esse descontrole parece decorrer da própria ciência e tecnologia, apontadas como fatores dessa instabilidade, que trazem no horizonte a ideia de riscos, perigos e incertezas.

Em sua perspectiva acerca do que denomina Modernidade Reflexiva, Giddens (1999) reconhece a existência de duas categorias de riscos: externos e fabricados. Enquanto o risco externo é oriundo da tradição ou da natureza, o risco fabricado é uma percepção geral de que algo está fora de controle e, nesse contexto, estão os riscos ambientais, a exemplo do aquecimento global, que são influenciados também pelo processo de globalização. Para Giddens (1999), o crescimento do risco fabricado faz surgir o "princípio de acautelamento" (ou de pre- caução) no início dos anos 1980, com as discussões ecológicas da Alemanha. Esse princípio propõe que se deva agir, no caso de questões ambientais, mesmo que exista incerteza científica em relação a elas. Disso depreendemos que se pode perceber como a incerteza do mundo é também baseada fundamentalmente na incerteza sobre os dados científicos que se têm à disposição.

Beck (1997) sugere que o conceito Sociedade de Risco permite não somente a compreensão da modernização reflexiva, mas aponta algumas reflexões para as soluções dos impasses da sociedade industrial. A Sociedade de Risco é uma fase do desenvolvimento da sociedade moderna, "[...] em que os riscos sociais, políticos, econômicos e individuais tendem cada vez mais a escapar das instituições para o controle e a proteção da sociedade industrial" (Beck, 1997, p.15). Na primeira etapa, o risco é individual e legitimado ainda dentro dos padrões da sociedade industrial; na segunda, os riscos dominam o debate e conflito públicos, políticos e privados. Assim, a sociedade ainda toma decisões com base na sociedade industrial, uma vez que suas organizações de interesse, sistema jurídico e político são obscurecidos por debates que se originam do dinamismo da Sociedade de Risco.

As perspectivas da Modernização Reflexiva e da Sociedade de Risco tornam evidente que são necessárias transformações sistêmicas capazes de prover entendimento quanto ao alcance das questões ambientais, na revisão da relação da sociedade industrial com os chamados recursos naturais. Além disso, os riscos sociais e ambientais parecem muito próximos das pessoas, despertando a busca pela segurança de um modo geral, mesmo que as ameaças sejam potencialmente direcionadas a alguns setores. Interessante pontuar que o risco somente é possível quando a sociedade passa a se ocupar do "futuro" e, nesse quesito, a definição central do conceito de 
desenvolvimento sustentável traz exatamente a ideia de um legado às "futuras gerações". 2

Como defende Beck (2010), a ciência passou a ser vista com certa desconfiança, alguns a apontando como ameaça social. No entanto, apesar da desconfiança em relação ao campo científico, esse é ainda o principal suporte de legitimação de discursos e de consensos buscados em âmbito internacional. Mesmo que as decisões estejam sendo tomadas com base em assimetrias socioambientais, econômicas e culturais, o alarme do risco global atinge todos os cantos do mundo. Esse conjunto de assimetrias, no pensamento de Beck (2010), estabelece aqueles que definem o risco e os que sofrem os efeitos dessas decisões.

Outra proposta de cunho reformista chama-se Modernização Ecológica e tem atuação voltada à resolução das questões ambientais a partir das lógicas do mercado, com apoio no desenvolvimento tecnológico (Mol, 2000). O resultado disso é que a sustentabilidade atualmente é um tema muito apropriado pelo setor industrial e empresarial como um todo e, dessa maneira, entendemos que a modernização ecológica obtém, no mundo prático, uma vantagem discursiva que se pretende impor, discursivamente, como a solução definitiva para a questão ambiental.

A modernização ecológica é um projeto tecnocrático, na medida em que as indústrias estão mobilizadas pelo uso de tecnologias não poluentes ou de baixo impacto ambiental, porém, sem tocar na estrutura da sociedade capitalista. Tanto a ecologização da economia, levada a cabo pela difusão de novas tecnologias para processos de produção e consumo, quanto a economização da ecologia, por meio da valoração econômica da natureza, considerada uma terceira força de produção (ao lado de capital e trabalho), são faces de uma mesma moeda, colocada em circulação pela modernização ecológica (Olivieri, 2009).

Para Caporal e Costabeber (2000), a visão ecotecnocrática é definida a partir da lógica econômica, liberal, que desconsidera as contradições econômicas, sociais e ambientais, estando fortemente calcada na modernização ecológica sob domínio do otimismo tecnológico. Além disso, tal visão não abre espaço para a biodiversidade, inclusive cultural, pregando a resolução para o problema do crescimento.

Logicamente, os discursos que admitem a ideia de sustentabilidade e justiça social incorporam a ideia de concepções partilhadas, mas isso seria possível diante de tantas assimetrias? Trata-se, portanto, da mesma crítica que se pode fazer ao pensamento tanto da modernidade reflexiva quanto da modernização ecológica, pensadas a partir de uma sociedade altamente industrializada e ocidental. São insuficientes para dar conta da complexidade social, econômica, política, ambiental e cultural do mundo.

Nesse cenário, em que aparecem diferentes interpretações sobre o futuro que a humanidade deve projetar a partir das escolhas feitas no presente, também florescem teóricos com propostas significativas mesmo antes da emergência de problemas ambientais de âmbito global. A começar por Capra (2006), para o qual a visão ecológica é base para a mudança social:

Enquanto o ambientalismo superficial se preocupa com o controle e a administração mais eficiente do

\footnotetext{
2 O "Relatório Brundtland" ("Nosso futuro comum"), publicado em 1987, apresentou a definição de desenvolvimento sustentável, que é repetida desde então: "o desenvolvimento que satisfaz as necessidades presentes, sem comprometer a capacidade das gerações futuras de suprir suas próprias necessidades.”
} 
meio ambiente em benefício do "homem", o movimento da ecologia profunda exigirá mudanças radicais em nossa percepção do papel dos seres humanos no ecossistema planetário. Em suma, requer uma nova base filosófica e religiosa. (Capra, 2006, p.402-3).

Para realizar a mudança no sistema de valores sociais que regem a sociedade como um todo, Capra (2006, p. 43) propõe a ecologia profunda, que é ancorada "[...] pela ciência moderna e, em especial, pela nova abordagem sistêmica, mas tem suas raízes numa percepção da realidade que transcende a estrutura científica e atinge a consciência intuitiva da unicidade de toda a vida". O autor se contrapõe à visão instrumental da natureza, que pressupõe que todos os demais entes devem estar subjugados aos interesses dos seres humanos.

Outro autor que postula a mudança de paradigma para o enfrentamento das questões ambientais é Enrique Leff, para o qual o chamado processo civilizatório que vivenciamos está baseado na "racionalidade econômica e instrumental que moldaram as diversas esferas do corpo social: os padrões tecnológicos, as práticas de produção, a organização burocrática e os aparelhos ideológicos do Estado" (Leff, 2001, p. 133). O papel da questão ambiental é justamente questionar os custos dessa racionalidade e estabelecer a necessidade de reformas democráticas.

O saber ambiental formulado por Enrique Leff questiona essa racionalidade como instrumento de dominação da natureza. Na sua linha de pensamento, o saber não pode ser reduzido ao mercado. $\mathrm{Da}$ mesma forma, Leff (2009) escreve que o ambiente é mais que a ecologia, é mais complexo, é "[...] um saber sobre as formas de apropriação do mundo e da natureza, através das relações de poder que têm sido inscritas nas formas dominantes do conhecimento" (2009, p. 16). Na visão de Leff (2010), o saber ambiental emerge como efeito dos processos de mudança social, que traz consigo novos valores e nova consciência.

Uma linha de interpretação de viés ambiental é trazida por Caporal e Costabeber (2000): trata-se da corrente ecossocial, que, em linhas gerais, contempla o ideário de mudanças estruturais, com apoio do conceito de ecodesenvolvimento, surgido nos anos 1970. Essa visão utiliza-se, ainda, dos discursos culturalista (cultura como instância fundamental da relação com a natureza) e ecossocialista (capitalismo verde não é capaz de resolver mazelas sociais).

$\mathrm{O}$ discurso ecossocial reúne, assim, várias fontes de influência de discursos emergentes, com ênfase na solidariedade entre as gerações futuras e presentes. Outro diferencial, em relação à visão ecotecnocrática à qual se contrapõe radicalmente, é o respeito às tecnologias tradicionais e também à biodiversidade e à cultura, concepção, portanto, contrária ao desenvolvimento de cunho liberal e crítico ao esverdeamento da economia. (Caporal \& Costabeber, 2000).

Após a apresentação das concepções sobre a relação homem-natureza, que circulam socialmente e na Sociologia e que auxiliam nosso gesto de interpretação dos discursos, podemos afirmar nosso lugar de observação. O paradigma teórico e político adotado neste artigo está comprometido com a construção da sustentabilidade da vida, isto é, estamos alinhados à corrente ecossocial e ao saber ambiental, perspectivas que podem impulsionar a construção de um espírito novo para o Jornalismo.

\section{Discurso jornalístico ambiental e enquadramento discursivo}

O discurso jornalístico ambiental está inserido na grande teia de discursos sociais sobre o tema. Os 
discursos vinculados a concepções ideológicas e que se relacionam de alguma forma com as condições descritas nas ideias da modernidade reflexiva, da sociedade de risco e da modernização ecológica são hegemônicos. A importância em se observar os discursos jornalísticos está associada ao papel condicionante dos meios de comunicação que são pautados na cobertura de eventos relacionados à área ambiental, no que concordamos com Carvalho (2011), em relação ao papel de reprodução seletiva na perspectiva de certos atores sociais. Isto é, os meios de comunicação, na seleção de seus enfoques, direcionam o modo de ver em relação às questões sociais, neglicenciando a complexidade das questões. Além disso, "as organizações mediáticas funcionam segundo lógicas e dinâmicas próprias que condicionam, necessariamente, a sua forma de cobertura das alterações climáticas." (Carvalho, 2011, p. 17).

O paradigma construcionista da notícia ${ }^{3}$ aponta que "[...] toda a representação é uma construção subjetiva da realidade" (Benetti, 2007, p. 110). Também é pressuposto dessas teorias que os meios estruturam a representação dos acontecimentos, devido, entre outros fatores, à organização do trabalho jornalístico e suas rotinas, estabelecendo tipos e formatos para dar conta de fatos inesperados. As notícias sobre meio ambiente normalmente se encontram no limite do jornalismo, isto é, no que se espera de sua atuação e no que, como processo complexo, ele retorna à sociedade, visto que, entre os fatos e seus relatos, há uma série de escolhas realizadas no âmbito das rotinas produtivas, que envolvem a seleção do que será ou não publicado e, mais importante, a forma que se dará aos relatos. O jornalismo é produto de sua própria institucionalização, entendida aqui como a legitimação das rotinas produtivas e dos valores a elas associados, em interação com outros atores sociais. Há, portanto, uma mobilização de diferentes esferas, de saber e de poder, aumentando a complexidade e disputas que são travadas e dirigidas ao jornalismo.

$\mathrm{Na}$ construção das notícias, destacam-se os processos de organização/seleção, significação/ valorização e publicização dos temas, que fazem parte de uma forma específica de organizar a representação dos fatos. Em relação ao meio ambiente, uma das maiores críticas dirigidas ao jornalismo é de ser um tema um tanto invisível, exceto quanto ao tempo da cobertura dos desastres. Isso poderia ser explicado pela tendência apontada pelas Teorias do Jornalismo de que o acontecimento jornalístico se volte para o inesperado, àquilo que rompe com a normalidade e que precisa ser recomposto dentro das representações culturais já consensuais na sociedade. Um exemplo recorrente é a cobertura de grandes enchentes em metrópoles mal planejadas, em que há uma simplificação do problema, apresentado como uma novidade ou como sendo a natureza uma vilã ou vingadora (Moraes \& Girardi, 2012).

Como o jornalismo vai buscar esses indícios de notabilidade, conforme Alsina (2009), baseado, sobretudo, no critério de variação, muitas questões e problemas são deixados de lado ao longo da cobertura jornalística. Pergunta-se o que há de novo, o que supera ou modifica algum padrão já estabelecido, sendo que não são questionados os padrões existentes. Dito isso, concordamos com

\footnotetext{
${ }^{3} \mathrm{O}$ termo notícia é utilizado neste artigo, prioritariamente, não como um gênero jornalístico que estaria em contraponto à reportagem, por exemplo, mas sim como o acontecimento jornalístico (a notabilidade dos fatos sociais) a partir das Teorias do Jornalismo. Desse ponto de vista, a notícia pode ter várias formas de apresentação narrativa e constituir-se nos gêneros jornalísticos. Analisamos o gênero jornalístico reportagem cujo foco seja a notícia ambiental.
} 
Benetti (2010) ao descrever essa lógica em seu lado perverso, com um grau de cinismo na percepção dos valores de certos fatos:

A perversidade dessa lógica, que contra qualquer argumento plausível mantém-se como estruturante do discurso jornalístico, é que grandes fenômenos sociais, cujo interesse público não poderia ser questionado sem constrangimento, geralmente não tem lugar no jornalismo porque se estabeleceram, historicamente, como invariantes (Benetti, 2010, p.146).

Percebemos assim que o acontecimento ambiental, assim como propôs Hannigan (1995), fica circunscrito às tipologias características do acontecimento jornalístico. Questionamos, sobretudo, a naturalização, operada pela ideologia, da exploração descabida dos bens naturais a favor do lucro, relacionada a desigualdades sociais e, em alguns casos, a ecocídios invisíveis. A mudança do clima pode ser entendida dessa forma, ou seja, é lenta e gradual, porém, crescente ao longo do tempo, com perspectivas de atingir em maior escala justamente os mais pobres ou vulneráveis.

Dentro dessa perspectiva, reafirmamos que o jornalismo tradicional, quando trata da temática ambiental sem compromisso com a defesa do meio ambiente e/ou da vida em todas as suas dimensões, é simplesmente jornalismo de meio ambiente. Sua prática se dá dentro dos limites da institucionalização do campo, legitimado e reconhecido por sua intervenção social empreendida por meio do produto notícia. Por entendermos a essencial contribuição do jornalismo à constituição de crenças e visões de mundo, vislumbrando o campo discursivo implicado nesse processo, pensamos que o Jornalismo Ambiental ainda está em construção, assim como uma sociedade sustentável. Esta, mesmo com iniciativas nos mais diversos recantos do planeta, ainda é um projeto para o futuro.
Entendemos o Jornalismo Ambiental como aquele que é praticado a partir da ideia da sustentabilidade e, assim, valoriza tanto a cultura e o meio ambiente quanto a economia e a política. Essa ideia deve permear as reportagens que buscam maior aprofundamento contextual e a oferta de diferentes visões de mundo, sendo, portanto essencial à pluralidade de fontes (Girardi et al., 2011). Trata-se de um jornalismo que busca o aprofundamento e por isso tem ênfase no processo de apuração da informação jornalística (Girardi \& Schwaab, 2008). Ao mesmo tempo em que é uma especialização e se organiza a partir do conhecimento sobre meio ambiente e suas interações (Fernandez, 2010), não é simplesmente uma especialidade, pois prioriza no seu exercício um comprometimento com uma visão cidadã (Bueno, 2007; Sorhuet, 2013). Por fim, o Jornalismo Ambiental olha para a sociedade a partir do saber ambiental e com as lentes da visão sistêmica, beneficiando, sobretudo, a informação e a cidadania (Girardi et al., 2006; Moraes, 2016).

Com a perspectiva da Análise do Discurso a partir de Michel Pêcheux, passamos a observar os discursos jornalísticos sobre meio ambiente, em especial diante da crise climática, associando-se as Teorias do Jornalismo brevemente discutidas até aqui à $\mathrm{AD}$.

$\mathrm{O}$ discurso, na perspectiva da $\mathrm{AD}$, não é um texto e suas significações. Pêcheux (1997) chama a atenção na sua formulação sobre o discurso como "efeito de sentido entre interlocutores". Trata-se de um processo dinâmico, desenvolvido de várias formas e em situações sociais determinadas. Importa perceber que as condições de produção são elas próprias constitutivas de uma prática discursiva.

As condições de produção do discurso foram destacadas por Pêcheux (1997) como a ligação das circunstâncias de um discurso e seu processo de produção, que devem ser levadas em conta e procuram 
suplantar a ideia de contexto e situação apontados pela linguística, pois são condições marcadas pela história e pela ideologia.

O discurso é definido como prática social, pois

[...] diz respeito a um conjunto de situações internas e externas ao ato discursivo, sempre relacionadas às posições de sujeito - os lugares que o sujeito vem ocupar no discurso. A prática se institui no quadro de certos sistemas de formação, estruturados e hierárquicos - embora mutáveis, pois não são congelados no tempo (Benetti, 2008b, p. 3).

Tomamos então o discurso como uma instância material concreta da relação mediada entre linguagem/pensamento/mundo. Dessa forma, a noção de ideologia configura-se como fundamental para desvendar os sentidos de qualquer discurso, que está, naturalmente, embriagado dela, pois ideologia "[...] não é X, mas o mecanismo de produzir X" (Orlandi, 2007, p.30). Observa-se, com isso, que o efeito imaginário entre linguagem e mundo é operado justamente a partir da ideologia, que "[...] não é ocultação, mas função da relação necessária entre linguagem e mundo" (Orlandi, 2010, p. 47).

O Jornalismo é considerado uma prática discursiva (Indursky, 1997), pois atua sob circunstâncias peculiares na produção do discurso, a partir de uma comunidade, e sob efeito ideológico de Formações Discursivas. O conceito de Formação Discursiva (FD) é entendido como "aquilo que, numa formação ideológica dada, isto é, a partir de uma posição dada numa conjuntura dada, determinada pelo estado da luta de classes, determina $o$ que pode e deve ser dito" (Pêcheux, 1997, p. 160, grifos no original) ou, ainda, como "o domínio do saber constituído de enunciados discursivos que representam um modo de relacionar-se com a ideologia vigente, regulando o que pode e deve ser dito, mas também o que não pode, não deve ser dito" (Indursky, 1998, p. 115).

Utilizamos o conceito de Formação Discursiva de caráter heterogêneo, entendida também como uma FD aberta. Isso porque entendemos que as contradições são inerentes à ideologia e, neste momento, da contradição, outros sentidos oriundos de outras formações podem ser observados.

O processo da prática discursiva jornalística passa pelos critérios sobre o que é ou não é notícia, os quais levam em conta questões socioculturais, estruturais dos meios de comunicação e, especialmente, a construção simbólica sobre o Jornalismo - a sua representação social. Essa construção de si relaciona-se às Formações Imaginárias e se pode se organizar a partir do ethos. ${ }^{4}$ Conceito formulado por Pêcheux (1997), formações imaginárias é colocado em termos dos horizontes imaginários sob os quais o sujeito que fala produz sua enunciação, dirigida ao interlocutor.

Indursky (1997, p. 28) aponta que o discurso representa as relações de força existentes entre os lugares sociais, por meio das formações imaginárias. Assim, podemos afirmar que o lugar discursivo tem relação com o lugar socialmente determinado e torna-se imprescindível para entender o funcionamento do "enquadramento discursivo". Ele é fruto de uma interação entre o campo jornalístico e outros campos pelo habitus (Bourdieu, 1997), estabelecido ainda pela relação do jornalista com suas fontes e organizado a partir de seu ethos discursivo, pois "As 'idéias' suscitam a adesão por meio de uma

\footnotetext{
4 “[...] define para os membros da comunidade jornalística que o seu papel social é de informar os cidadãos e proteger a sociedade de eventuais abusos do poder, ou seja, toda a concepção do jornalismo enquanto “contra-poder”' (Traquina, 2005, p. 202).
} 
maneira de dizer que é também uma maneira de ser" (Maingueneau, 2008, p. 29). Assim, quando pensamos a noção de lugar discursivo, abre-se a perspectiva de que o enquadramento discursivo tem tanto um valor social (na medida em que legitima o campo para o relato do acontecimento) quanto reforça uma relação imaginária entre o Jornalismo e a sociedade.

Por conseguinte, entendemos que a noção de prática discursiva junto à de lugar discursivo do Jornalismo é fundamental para a compreensão da noção de enquadramento discursivo, dado que o Jornalismo tem a tarefa prioritária de enquadrar os acontecimentos.

Enquadramento descreve uma teoria de esquemas interpretativos, tomada por Goffmann na obra Frame Analysis (1986) e que tem servido a pesquisadores de Comunicação e de Jornalismo. ${ }^{5}$ A noção de enquadramento foi utilizada por Tuchman (1993) em situações mais amplas da profissão do jornalista, na medida em que estabelece uma tipologia dos acontecimentos. Conforme Tuchman (1993), as hard news (notícias duras) são consideradas aquela dadas em tempo real, relacionados a fatos que, caso não sejam noticiados, perdem seu valor junto ao público. Já as soft news (notícias brandas), ao contrário, são informações de contexto, de interesse humano e sem o caráter imediatista em relação à sua publicação. A tipologia dos acontecimentos é uma forma de enquadramento consensual entre os jornalistas que, diante de um determinado fato, passam a tratá-lo de uma forma padronizada. Nesse ponto, podemos compreender que enquadramento pode estar relacionado a variados níveis de interpretação da informação que será ofertada ao público.

A dimensão discursiva do enquadramento, trazida por Gitlin (1980), indica que os “[...] enquadramentos de mídia são padrões resistentes de cognição, interpretação e apresentação, de seleção, ênfase e exclusão" (Gitlin, 1980, p. 7). Dizemos então que o enquadramento jornalístico oferta sentidos, organizando discursivamente o conhecimento sobre determinada temática e, por esta relação discursiva, preferimos chamar de "enquadramento discursivo".

Antes de apresentar as análises e discussões da pesquisa, retomamos, de forma sintética, os pressupostos teóricos apresentados, que indicam nosso entendimento sobre o enquadramento discursivo: a) o discurso jornalístico ambiental funciona no limite dos constrangimentos organizacionais (a pressão da rotina produtiva, que impõe tempo e espaço para a produção da notícia, é associada a valores empresariais, como, por exemplo, a busca de manutenção de leitores e anunciantes) e em relação direta com os discursos ambientais hegemônicos na sociedade; $b$ ) o discurso é entendido como efeito de sentido entre interlocutores (Pêcheux, 1997), logo, nosso interesse não é o texto em si, mas "como ele significa"; c) a partir do paradigma construcionista das teorias da notícia, há uma possibilidade de que os discursos sejam permeados por outros, na disputa entre Formações Discursivas; d) o enquadramento jornalístico parte de alguns critérios de atuação do jornalista, portanto, de seu lugar de fala, institucionalizado, entendido a partir das Formações Imaginárias.

\footnotetext{
5 "Em Gender Advertisements (1976) e Forms of Talk (1981), Goffman prossegue algumas das ideias desenvolvidas em Frame Analysis e dedica mais tempo aos enquadramentos institucionais, nomeadamente aos propostos pelos media. Nessas obras, Goffman retoma e aprofunda as suas primeiras teorias, nomeadamente de A Apresentação do Eu na Vida Quotidiana (1959) e de Estigma (1963), recorrendo com frequência a exemplos retirados dos meios de comunicação social. Forms of Talk contém especificamente um ensaio sobre rádio" (Silveirinha, 2005, p. 3).
} 


\section{O enquadramento discursivo da Rio+20 na revista Época}

Antes de apresentarmos as análises e discussões, destacamos que apresentaremos nosso corpus já devidamente recortado em Sequências Discursivas. O procedimento metodológico denomina Sequência Discursiva (SD) como "o trecho que arbitrariamente recortamos para análise e depois utilizamos no relato de pesquisa" (Benetti, 2008a, p. 113). A apresentação destas SD's foi realizada a partir dos objetivos de observação do discurso como um todo, buscando-se compreender as Formações Discursivas no discurso. Em cada $\mathrm{SD}$, encontramos marcas discursivas, ou "as expressões que constroem o caminho em direção ao sentido nuclear da FD", conforme Benetti (2008a, p. 113). As marcas estão destacadas em negrito para a apresentação das análises sobre os efeitos de sentido, com as quais temos subsídios para formular o enquadramento discursivo que está ancorado na FD predominante.

O enquadramento discursivo é então entendido como um dispositivo de análise para perceber a articulação dos discursos a partir da prática discursiva específica do jornalismo. O objetivo da análise foi compreender como o discurso sobre a mudança climática articula a noção de futuro e, por consequência, a relação homem-natureza, a partir da materialidade discursiva - a reportagem de capa da revista Época, edição número 735 , publicada em 18 de junho de 2012.

Com a análise realizada, encontramos as duas principais formações discursivas: a predominante, Formação Discursiva Ecotecnocrática, e uma emergente, a Formação Discursiva Ecossocial, ambas constituídas a partir do entendimento sobre a questão ambiental e seus desafios em relação ao futuro. Resumimos, na Tabela 1, os principais eixos de cada Formação Discursiva.

TABELA 1 - Eixos das Formações Discursivas da Reportagem de Época.

\begin{tabular}{ll}
\hline \multicolumn{1}{c}{$\begin{array}{c}\text { Formação Discursiva } \\
\text { Ecotecnocrática }\end{array}$} & $\begin{array}{c}\text { Formação Discursiva } \\
\text { Ecossocial }\end{array}$ \\
\hline $\begin{array}{l}\text { Enquadramentos se rela- } \\
\text { cionam diretamente à lógi- } \\
\text { ca liberal econômica, não }\end{array}$ & $\begin{array}{l}\text { Enquadramentos estão } \\
\text { ancorados em aspectos } \\
\text { da ecologia profunda, in- } \\
\text { cluindo a crítica ao con- } \\
\text { incluindo nesta formação } \\
\text { qualquer questionamento às } \\
\text { sumo, ao crescimento infi- } \\
\text { contradições econômicas, } \\
\text { nito, às metas econômicas } \\
\text { das do sistema. }\end{array}$ \\
$\begin{array}{ll}\text { Sentidos de progresso, cres- } \\
\text { cimento, modernização e } \\
\text { otimismo tecnológico. }\end{array}$ & $\begin{array}{l}\text { Sentido de respeito à am- } \\
\text { pla biodiversidade e aos } \\
\text { saberes ambientais. }\end{array}$ \\
Visão antropocentrista & Visão ecocêntrica \\
\hline
\end{tabular}

FONTE: Elaboração própria.

Começamos a exemplificar a maneira pela qual os enquadramentos discursivos encaminham e articulam os sentidos, a partir da observação da capa da edição analisada (Figura 1). A revista definiu como Edição Verde, na qual traz as expectativas sobre o tema ambiental e a realização da Rio+20. A capa é analisada como um conjunto entre imagem ilustrativa e sua manchete: "Rio+20: O futuro dele depende de nós/O desafio de garantir riquezas e recursos para as próximas gerações". A ilustração tem como base uma fotografia da paisagem do Rio de Janeiro, onde aparecem apenas os sistemas naturais, características do relevo e da Mata Atlântida. Reforçando a questão do Rio de Janeiro, aparece o Cristo Redentor, monumento internacionalmente conhecido e que é uma marca da cidade. Em primeiro plano, é inserida outra imagem, a de um bebê em posição fetal e que dorme sob uma grande folhagem. 


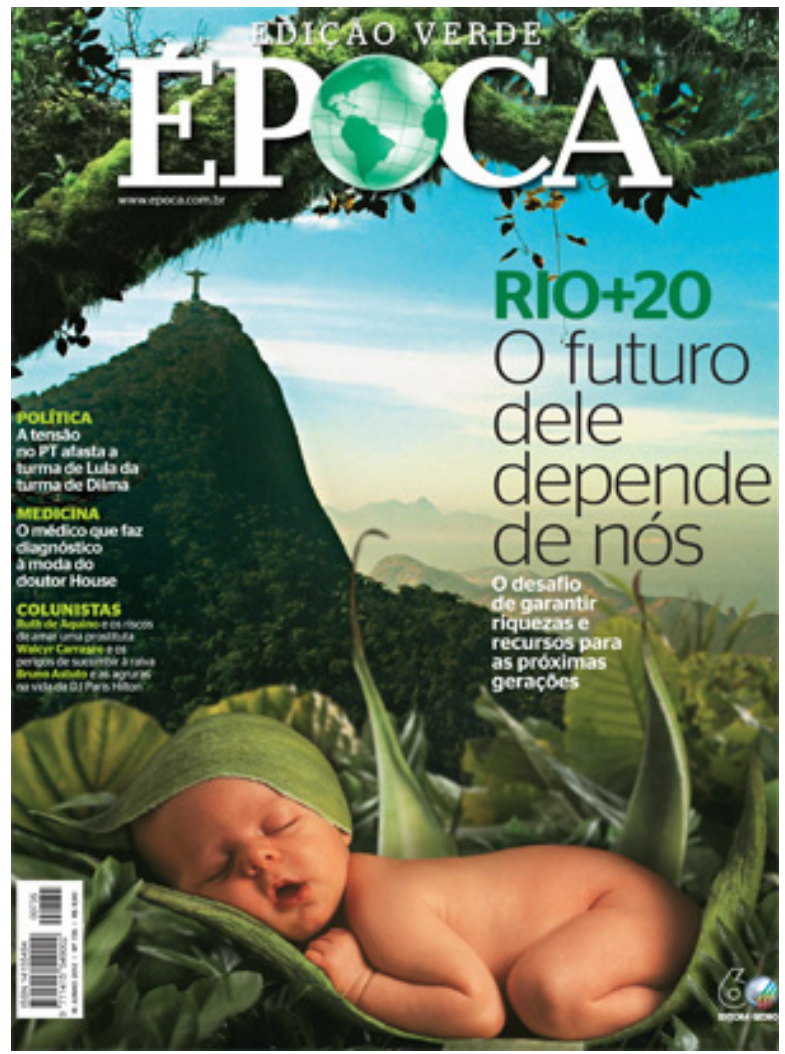

FIGURA 1. Capa Época, Edição Verde.

O que chama a atenção, como um ponto focal na construção discursiva da capa, é o bebê, que está em primeiro plano, na parte inferior da capa, mas que é destacado como elemento principal. É a partir de sua imagem que o discurso está sendo enunciado, em seu lugar. Isso porque, como humanos, sabemos da fragilidade do recém-nascido, que depende de cuidados constantes para sobreviver, receber alimento e proteção, condições para seu crescimento e desenvolvimento.
Ele dorme. O seu berço é formado por uma folhagem que o acolhe, como uma concha ou uma grande mão. Ele é tranquilo, inocente. ${ }^{6}$ Ao lermos o título "O futuro dele depende de nós", associa-se a dependência entre as gerações. $\mathrm{O}$ bebê está num lugar longe da cidade, local onde "nós" estamos definindo o seu futuro. A frase "O desafio de garantir riquezas e recursos para as próximas gerações" reforça a ideia de um compromisso de nossa geração com o futuro.

O discurso sobre o futuro está ligado diretamente ao uso de "riquezas e recursos", ou seja, é um discurso de viés antropocêntrico. O sentido mobiliza a ideia de que nós (humanos) temos a chave para organizar e utilizar os recursos naturais; associa-se a ideia de que os recursos já estejam à nossa disposição. Ou seja, é um efeito de sentido de que somos proprietários desses recursos e podemos usufruí-los de várias e quaisquer maneiras. Dessa forma, indicamos que o discurso de Época é voltado à ideia de um progresso incessante e contínuo, possível a partir de um chamado uso racional dos recursos do planeta. Também indica que há uma supremacia do homem em relação à natureza, pois o futuro "está em nossas mãos". Identifica-se, portanto, a FD Ecotecnocrática.

Se, de um lado, esse discurso de Época implica a propriedade da natureza, por outro, institui um mínimo de responsabilidade em relação ao futuro, pois indica que há um desafio, o de deixar um legado para as próximas gerações, para que continuem produzindo riquezas no futuro. Época constrói, dessa forma, um modo político de encaminhar as soluções para a crise ambiental, de forma a pensar

\footnotetext{
${ }^{6}$ A fotografia usada nesta composição é de Anne Geddes. A fotógrafa australiana cria imagens e produtos amados em todo o mundo. Já vendeu milhões de livros. Sua especialidade são as fotos de bebês, fofos, acomodados em folhas, flores, vegetais, em ninhos de pássaros, saindo de ovos, ou com suas mães, ainda em vasos e jardins, entre tantas outras produções diversas. Todas trazendo a marca de pureza e de uma harmonia total do bebê com seu ambiente. Uma de suas fotos mais vistas é composta por dois bebês sentados dentro de grandes repolhos, com chapeuzinhos de repolho inclusive, voltados um para o outro. O seu site é campeão de acessos: <http://www.annegeddes.com>.
} 
uma saída a partir de elementos que estejam ao nosso alcance (de nossa geração) para a construção de um futuro que seja acolhedor (tal qual a imagem de Anne Geddes do bebê sob a grande folha verde). A reportagem principal desta edição de Época chama-se "Quanto vale o futuro" (páginas 70 a 78) e indica o caminho que será trilhado no texto, questionando o "saldo" da conta da depredação ambiental, mas também demonstrando o quanto a falta de investimentos está ligada à crise econômica mundial.

\section{SD1: Quanto vale o futuro (título)}

SD2: A Rio+20 começa com uma certeza: temos de investir hoje para que exista um amanhã. $E$ uma dúvida: como fazer isso em tempos de crise? (linha de apoio)

A necessidade de ação pelo futuro está ligada diretamente às questões econômicas. A natureza é coisificada como recurso planetário. Também há a ênfase ao uso das tecnologias para evitar a catástrofe.

Na SD3, tem-se o efeito de sentido de que a disputa em torno da questão ambiental no capitalismo está em como movimentar o próprio sistema (para que tudo permaneça igual) e, por isso, a principal dúvida é em relação à conta que esta mudança que se afirma necessária, passando-se, dessa forma, ao debate sobre formas de financiamento dessa "nova economia".

SD3: É por isso que a Rio +20 - o novo encontro organizado pela $\mathrm{ONU}$, que reúne líderes ou representantes de 180 países no Rio de Janeiro entre os dias 13 e 22 não poderia ocorrer num momento mais inoportuno. Estados Unidos e Europa estão mergulhados na maior crise econômica desde os anos 1930. O tamanho das dívidas e a retração econômica geraram desemprego recorde nos EUA e ameaçam a própria sobrevivência da moeda europeia. Premidos por soluções imediatas para sair do buraco neste ano, há pouca disposição política para pensar em investimentos que melhorarão a vida das próximas gerações. No ano passado, a população do planeta alcançou 7 bilhões de pessoas. Está cada vez mais evidente que não é possível dar riqueza e conforto material para toda essa gente, nos padrões atuais de consumo e com as tecnologias correntes de produção.

O inoportuno trazido pelo enquadramento da revista é justamente a crise econômica mundial, que atinge também os países mais ricos e que traria a falta de vontade política para a efetivação da mudança. $\mathrm{O}$ trecho em destaque mostra que o número de 7 bilhões de pessoas no mundo evidencia que não há como manter o mesmo padrão de consumo e as mesmas tecnologias de produção.

Sobre a questão climática, a postura da revista enquadra os chamados céticos do clima como "pseudocientistas" que insistem em "propagar bravatas". O aquecimento global é dado como certo e com consequências sobre a cadeia de alimentos, a inundação de cidades e o agravamento de fenômenos climáticos como secas e inundações (SD4).

\begin{abstract}
SD4: A atividade humana está alterando o clima da Terra - sim, apesar de alguns pseudocientistas insistirem em propagar bravatas, é consenso entre todos os pesquisadores sérios que a temperatura média da Terra está subindo graças à emissão de gases poluentes. A persistir nesse ritmo, é possível que, no final deste século, ela tenha aumentado 4 graus Celsius. Tamanha alta bastaria para desmanchar a cadeia produtiva de alimentos, inundar cidades e agravar eventos como secas e inundações.
\end{abstract}

Os sentidos que emergem da reportagem indicam que as causas estruturais do capitalismo não entram em debate. Ao contrário, é pela via da economia que os problemas ambientais devem ser encarados. O colapso é colocado como um espaço 
de relação urgente com as ações em relação ao futuro, no entanto, não são apresentadas outras opções que de fato poderiam transformar a relação ocidental do homem em relação à natureza.

Dessa forma, a questão econômica é logo inserida no discurso, precisamente no instante em que o aquecimento custaria $20 \%$ do PIB global em 2050, caso nada seja feito para minimizar o ritmo do aquecimento. Os dados de catástrofes como furacões no EUA e as chuvas no Brasil entre 2008 e 2011 reforçam a ideia dos estragos do aquecimento.

SD5: Num levantamento encomendado pelo governo britânico, o economista Nicholas Stern, da London School of Economics e da Universidade de Leeds, afirmou que o aquecimento custaria $20 \%$ do PIB global por volta de $\mathbf{2 0 5 0}$, se nada fosse feito. Uma amostra disso seria a profusão de eventos semelhantes ao Furacão Katrina, que causou 1.836 mortos e prejuízos de US\$ 81 bilhões em 2005 nos EUA. Ou à sequência de sete chuvas recordes no Brasil entre 2008 e 2011, que culminou com a tragédia na região serrana do Rio, com centenas de mortos.

A ênfase é pela relação econômica e pelo uso de recursos naturais. Discurso mais repetido pelas sequências discursivas relacionadas à conferência, essa visão é predominante desde os documentos da própria ONU, inclusive citados pela revista, como o relatório Limites do Crescimento de 1972. A ideia chave é de que o crescimento não poderia ser considerado ilimitado pelos governos, já que os "recursos naturais" limitam esse crescimento (SD6).

SD6: A necessidade de mudar nossos rumos no mundo começou a ficar clara nos anos 1970. Um grupo de pesquisadores reunidos pela academia de ciências italiana, o Clube de Roma, juntou todo o conhecimento disponível e lançou o relatório Limites do crescimento, em 1972. O estudo previa o esgotamento futuro de recursos minerais e energia - levantamentos atuais mostram que as previsões foram precisas. Ainda em 1972, em Estocolmo, a ONU promoveu a primeira conferência internacional de meio ambiente e desenvolvimento, mãe da Rio-92 e avó da Rio+20. Foi a primeira vez que os governos começaram a levar a sério a ideia de que não seria possível conseguir crescimento econômico ilimitado sem considerar a oferta limitada de recursos naturais.

Na SD7, surge a questão do Produto Interno Bruto como medida incapaz de dar conta da destruição da natureza, decorrente do crescimento econômico. O questionamento do PIB foi trazido por uma fonte do PNUMA (Programa das Nações Unidas para o Meio Ambiente), programa que também estava em discussão durante a Rio+20.

SD7: "Quando se mede geração de riqueza apenas pelo PIB, vemos ganhos enormes. Mas isso esconde o que perdemos em integridade dos ecossistemas, nosso patrimônio natural", diz Moustapha Kama Gueye, do Pnuma. "Fizemos uma economia que cresce exaurindo os recursos de que ela precisa para continuar gerando riqueza no futuro".

A fonte do PNUMA é utilizada para a construção do sentido de que o PIB esconde a perda do patrimônio natural. Essa contradição está na base do sentido corrente de desenvolvimento sustentável, noção em si contraditória, pois, sendo inerente a uma economia que busca crescer mais e mais, desde que esse desenvolvimento não afete a sua própria continuidade nas próximas gerações. Embora o sentido seja de mesma base ecotecnocrática, indicamos que o enquadramento, ao apresentar essas contradições, mostra-se como um espaço de deslizamento de sentidos que podem, ao longo do tempo, colaborar para enquadramentos diferenciados, demonstrando a amplitude da problemática.

A tese do aquecimento global é colocada nos termos do IPCC (sigla de Intergovernmental Panel on Climate Change). Isso destaca a atividade 
humana na emissão de gases, especialmente pelo desmatamento e queima de combustíveis fósseis. Os eventos mais catastróficos, no entanto, são minimizados, dizendo-se que pode haver exagero, porém, o descuido ambiental é considerado oneroso. Ao final da SD8, o tema da economia verde é lançado, com o fim de questionar o custo para esta "guinada".

SD8: $O$ custo econômico da devastação ficou mais claro com as crescentes evidências de que a atividade humana contribui para o aquecimento global. Em 2007, o painel de cientistas reunidos pela ONU para estudar o clima, o IPCC, concluiu que o planeta está esquentando além do natural por causa de gases emitidos por atividades como desmatamento ou queima de combustíveis fósseis. Os mais pessimistas pintaram cenários no fim deste século que lembram cenas trágicas de ficção científica. É bem provável que haja exagero nesse catastrofismo, mas não há dúvida de que o descuido ambiental é oneroso. Quanto custaria, então, dar uma guinada rumo a uma economia mais limpa?

O enquadramento da "economia mais limpa" é o mercado, por isso a ideia de lucro tanto para produtores quanto para a natureza (SD9). O "retorno financeiro imediato" da reciclagem de alumínio é um exemplo. O discurso está direcionado em como fazer girar a roda da economia a partir de negócios "verdes" ou da chamada Economia Verde, ou seja, o discurso da revista apresenta um tom reformista, sem tocar em questões estruturais do tema ambiental.

SD9: O mercado de carbono na Europa enfrenta a maior baixa desde o início dos pregões, em 2005. Não há resposta simples. Algumas opções de menor impacto ambiental dão retorno financeiro imediato. É o caso da reciclagem de latas de alumínio. Ela reduz a necessidade de extração de matéria-prima (bauxita), emite $95 \%$ menos gases nocivos ao clima e consome $95 \%$ menos energia do que fazer uma lata nova. "É lucrativo para os produtores e para a natureza", diz Mônica Messemberg, diretora de relações institucionais da Confederação Nacional da Indústria (CNI).

Como retornos a longo prazo, as iniciativas de aterros sanitários podem incluir a canalização de gás metano (um dos principais gases de efeito estufa), que é considerada uma alternativa ecológica, porém, dentro da lógica de mercado, sendo indicada para aqueles que pensam em "retorno a longo prazo". A oportunidade não é pelo aspecto ambiental, mas pelo foco do negócio, pela geração de lucro (SD10).

SD10: Outras iniciativas dependem da vontade, da capacidade e da oportunidade para pensar em retorno a longo prazo. Um exemplo é dado pelos aterros sanitários. A decomposição da matéria orgânica neles exala gás metano. É o que dá o cheiro ruim ao lixo. Lançado na atmosfera, ele tem um poder 23 vezes superior ao do gás carbônico de agravar o aquecimento global. A alternativa ecológica é canalizar o metano e queimá-lo em geradores especiais.

Nesse cenário de investimentos a longo prazo, surge então o apelo ao papel dos governos como parceiros da iniciativa privada (SD11). O principal exemplo é o investimento em transportes coletivos limpos, como o metrô, que diminui a poluição dos automóveis individuais nas grandes cidades.

SD11: Muitos investimentos com prazos maiores de maturação exigem ações do governo em parceria com a iniciativa privada - seja no papel de regulador do mercado, seja assumindo parte do risco. Tome o exemplo da poluição do ar provocada pelos automóveis nas grandes cidades. Só em São Paulo, ela mata 7 mil pessoas por ano, segundo o pesquisador Paulo Saldiva, da Universidade de São Paulo (USP). Sem falar na perda de produtividade causada pelos congestionamentos. Nada disso será resolvido sem a construção de sistemas de transporte coletivo limpos e eficazes, como o metrô, que exige o envolvimento do poder público. 
A SD11 aponta uma solução ecologicamente correta, de investimento no transporte coletivo e, junto a isso, reforça as questões econômicas, pois o trânsito engarrafado gera "perda de produtividade". Isso demonstra o enquadramento tendendo ao fechamento de sentido na formação discursiva. Mesmo percebendo alguns deslizamentos, vemos que a narrativa sempre tenta prendê-los, organizando-os dentro do seu aspecto ideológico principal.

O conjunto de sequências discursivas com enfoque econômico reafirma a predominância de um discurso reformista e calcado na visão antropocêntrica em relação à natureza. Fica evidente, ainda, que, mesmo com pequenas aberturas a fontes que contestam a versão única da Economia Verde, não há propriamente um debate com o campo ambientalista mais radical, atores que estavam também representados durante a Rio+20, na realização paralela da Cúpula dos Povos pelo fórum das Organizações Não Governamentais. ${ }^{7}$ A escolha de fontes e ângulos da reportagem, dessa forma, funciona como um fechamento discursivo ao diferente.

A crise financeira da Europa derrubou o mercado de carbono (SD9) e desestimulou os empreendimentos nesse sentido. Porém, a revista aponta novamente que as ações de longo prazo são tomadas também a partir de momentos de crise - e, apesar da crise, como vemos na SD12. Em decorrência disso, os investimentos que geram mais empregos estariam dentro da plataforma do desenvolvimento sustentável:

SD12: Tempos de crise exigem medidas de visão. Em 2008, no início do abalo econômico, os governos anunciaram que injetariam dinheiro em obras de infraestrutura que gerassem desenvolvimento sustentável econômica e ecologicamente, em áreas como energia eólica ou construções eficientes. Os resultados desses investimentos serão avaliados agora na Rio+20. Um estudo feito pela Universidade de Massachusetts, nos EUA, mostra que os mesmos dólares que geram 3,7 empregos na indústria petroquímica criam nove na energia solar ou 15 em transportes de massa, como trem ou metrô.

Como o enquadramento é pelo valor movimentado em termos financeiros e pelos empregos gerados nas iniciativas da economia verde, a revista coloca um impasse em que a solução e o problema estão num mesmo patamar: a economia. Dessa forma, o alinhamento discursivo é dado pela Formação Discursiva Ecotecnocrática, porém, percebemos deslizamentos para a Formação Discursiva Ecossocial, enfatizando novas formas de consciência ambiental, com destaque dado às novas gerações (SD13):

\begin{abstract}
SD13: “Alguns céticos argumentam que só é possível investir em economia verde num período de prosperidade", diz Camila, do IIED. "Mas outros insistem que só teremos enriquecimento duradouro se reconstruirmos nossas economias em bases mais sustentáveis." O tradicional slogan verde era "pense globalmente, aja localmente". Sua nova versão é "pense no futuro, aja no presente".
\end{abstract}

Com a crise instalada, o meio ambiente pode ser a solução para gerar uma economia mais duradoura, embora muitos céticos apontem que só há investimentos em tempos de prosperidade. Agir localmente e pensar globalmente, slogan ecológico bastante disseminado, tem uma nova versão segundo a revista. É pensar no futuro e agir no presente. A SD13 traz a componente de esperança sobre o que é

\footnotetext{
${ }^{7}$ O Fórum Brasileiro de ONGs e Movimentos Sociais para o Meio Ambiente e o Desenvolvimento (FBOMS) foi responsável pela organização da Cúpula dos Povos, evento paralelo à Rio+20, com objetivo de dar espaço a movimentos sociais e sociedade civil.
} 
possível fazer ainda hoje para melhorar o ambiente para as próximas gerações.

Esse enquadramento, dentro das expectativas de construção de futuro, gera um espaço de abertura a um caminho ético, como destaca Bartholo Jr.:

\begin{abstract}
Nossa questão central não é a de uma ética futura, ou seja, uma ética a se configurar num ponto a ser ainda atingido no tempo, mas sim uma ética que hoje se preocupa com as consequências de nossos atos para com as gerações futuras. Uma ética que não se fundamenta num contrato inter pares, pois ela se refere a relações radicalmente assimétricas: as gerações futuras são vulneráveis a nossos atos, mas a recíproca não é verdadeira (Bartholo Jr., 2001, p. 172 , grifos do autor).
\end{abstract}

Assim, a constituição política do discurso se dá pela mobilização de um sentido de possibilidade, o futuro, nesse contexto, relacionado a uma ética de responsabilidade. Destaca-se, no entanto, que esse atravessamento da Formação Discusiva Ecossocial é bastante sutil, visto que a ética que se vislumbra no enquadramento é ainda ancorada nos aspectos do progresso e crescimento econômico em primeiro plano, entendendo-se, dessa forma, a natureza como um "recurso a ser explorado".

Observando-se os eixos do discurso de Época, apresentados tanto na capa quanto na reportagem analisada, podemos afirmar que há deslizamento do sentido para uma ética com o futuro (novas gerações).

No âmbito da Análise de Discurso de Pêcheux, o deslizamento de sentido é entendido como um espaço de falha, ou seja, é um lugar no qual as disputas de sentido que circulam na sociedade buscam o fechamento da Formação Discursiva. O fechamento é colocado pela paráfrase, que se repete, nesse enquadramento analisado, pelo retorno frequente ao ambiente econômico, às soluções tecnológicas para a continuidade do modo de vida capitalista, ou seja, um posicionamento reformista. Já o deslizamento do sentido é aquilo que escapa da Formação Discursiva predominante, no qual a contradição entre a relação entre o homem e a natureza emerge, mesmo que rapidamente. O deslizamento é o espaço da polissemia, e tanto pode estar a serviço do discurso hegemônico como apontar para outro lugar de sentido, lugar do equívoco (Orlandi, 1993). Pode a ética com as futuras gerações estar a serviço da manutenção do enquadramento da exploração, mesmo que esteja o discurso baseado na escassez de recursos. Porém, como ponto de ruptura e de polissemia, um deslizamento pode contradizer o discurso da FD predominante.

\section{Considerações finais}

A questão ambiental é sempre permeada por abordagens distintas, atores e temas que sobressaem, conflitos e definições, nem tanto definitivas. Assim, a mudança climática está se constituindo na atualidade como a questão ambiental de maior alcance e abrangência, estando associada a grandes catástrofes de impacto social.

Como resposta do sistema capitalista, o termo Economia Verde surge no horizonte do debate global relativo ao conceito de desenvolvimento sustentável. A Economia Verde se coloca como operadora do sistema para uma leve mudança em direção a uma economia chamada de economia lim$p a$. Na realização da $\mathrm{Rio}+20$, esse novo paradigma estava estabelecido como um princípio norteador do debate ambiental global.

O lugar discursivo do Jornalismo traz a legitimação social no relato dos acontecimentos e, além disso, planta uma relação imaginária e de credibilidade junto aos seus públicos. Desse lugar 
privilegiado, entendemos que o Jornalismo flexiona o enquadramento discursivo, um dispositivo de análise que utilizamos para observar os efeitos de sentido do texto jornalístico e suas respectivas Formações Discursivas.

$\mathrm{Na}$ apresentação de seu discurso, a revista Época operou seu enquadramento com ênfase na economia a partir de um discurso hegemônico, porém, trouxe alguns elementos de fundo ecossocial, os quais sublinhamos na apresentação e discussão dos resultados. Dessa forma, identificamos uma FD Ecotecnocrática com leve atravessamento da FD Ecossocial. O enquadramento de Época sobre as escolhas para o futuro é, portanto, dado a partir das inovações tecnológicas, tendo como realidade o aquecimento global e apresentando uma visão antropocêntrica, por vezes catastrófica, porém, comedida em relação a mudanças estruturais. Com isso, a relação homem-natureza que perpassa o enquadramento discursivo é dada a partir da lógica econômica; no entanto, em pequenas brechas, cintilam conceitos de modificação da consciência em relação à solidariedade intergeracional.

Esse resultado de enquadramento discursivo na reportagem analisada ratifica que os discursos hegemônicos na sociedade não estão abertos a

\section{Referências}

Alsina, M. R. A construção da notícia. Petrópolis/RJ: Vozes, 2009.

Bartholo Jr., R. A mais moderna das esfinges: notas sobre ética e desenvolvimento. In: Bursztyn, M. (Org.). A difícil sustentabilidade: política energética e conflitos ambientais. RJ: Garamond, 2001. p. 27-40.

Beck, Ü. A reinvenção da política: rumo a uma teoria da modernização reflexiva. In: Beck, Ü; Giddens, A. E Lash, S. (Orgs.). Modernização reflexiva. São Paulo: Ed. da Unesp, 1997. p. 11-72; 207-218. uma visão de mundo ecocêntrica. Dessa forma, ao articular fontes, temas e ângulos da reportagem, a revista se dirige a um público que, em tese, pensa desse mesmo lugar. Todavia, a disputa na construção de sentidos é sempre colocada como possibilidade a partir de Michel Pêcheux (1997). Logo, consideramos que há um pequeno espaço em que falhas do discurso do projeto ecotecnocrático apareçam, a partir de uma visão ecossocial, embora de forma bastante sutil e limitada, conforme a análise apresentada.

$\mathrm{Na}$ reportagem de Época, observamos o silenciamento e a ausência de fontes e visões diferenciadas, gerando uma simplificação de um tema amplamente complexo e urgente, como é o caso da mudança do clima, especialmente quando temos um verdadeiro desafio civilizacional em relação às escolhas sobre nosso futuro. Mesmo com a possibilidade de abordar outras questões, oriundas dos movimentos sociais presentes na Cúpula dos Povos, por exemplo, a revista selecionou apenas o espaço hegemônico do discurso oficial, ligado aos predicados da modernização ecológica. Portanto, o debate amplo, que deveria ser fomentado de forma relevante pelo Jornalismo, não se coloca no horizonte, diminuindo, assim, a sua legitimação social.

Beck, Ü. Sociedade de risco: rumo a uma outra modernidade. São Paulo: 34, 2010.

Benetti, M. A ironia como estratégia discursiva da revista Veja. Líbero, São Paulo: Cásper Líbero, Ano X, 20, 27-46, 2007. Disponível em: $<200.144 .189 .42 /$ ojs/index.php/ libero/article/download/4644/4368>.

Benetti, M. Análise do Discurso em jornalismo: estudo de vozes e sentidos. In: Lago, C.; Benetti, M. (Org.). Metodologia de pesquisa em Jornalismo. 2. ed. Petrópolis/RJ: Vozes, 2008a. p. 107-122. 
Benetti, M. O jornalismo como gênero discursivo. Galáxia, 8(15), 13-28, 2008b. Disponível em: <http://revistas.pucsp. br/index.php/galaxia/article/viewFile/1492/964>

Benetti, M. O jornalismo como acontecimento. In: Benetti, M.; Fonseca, V. P. da S. (Orgs.). Jornalismo e acontecimento: mapeamentos críticos. Florianópolis: Insular, 2010. p. 143-164.

Bourdieu, P. Sobre a televisão. Rio de Janeiro: Jorge Zahar, 1997.

Bueno, W. da C. Comunicação, jornalismo e meio ambiente: teoria e pesquisa. São Paulo: Mojoara, 2007.

Caporal, F. R.; Costabeber, J. A. Agroecologia e desenvolvimento rural sustentável: perspectivas para uma nova extensão rural. Agroecologia e Desenvolvimento Rural Sustentável, 1(1), 16-37, 2000.

Capra, F. O ponto de mutação: a ciência, a sociedade e a cultura emergente. São Paulo: Cultrix, [1982] 2006.

Carvalho, A. (Org.). As alterações climáticas, os media e os cidadãos. Coimbra: Grácio Editor, 2011.

Fernandez, R. La sostenibilidad: una nueva etapa en el periodismo ambiental y en el periodismo en general. $D E$ LOS, 3(8), 2010. Disponível em: <http://www.eumed.net/ rev/delos/08/rfr.pdf>

Giddens, A. Mundo em descontrole: o que a globalização está fazendo de nós. Rio de Janeiro: Record, 1999.

Girardi, I. M. T.; Schwaab, R. T. (Orgs.). Jornalismo Ambiental: desafios e reflexões. Porto Alegre: Dom Quixote, 2008.

Girardi, I. M. T.; Massierer, C.; Schwaab, R. T. Pensando o Jornalismo Ambiental na ótica da sustentabilidade. UNIrevista, 1(3), 2006.

Girardi, I. M. T.; Camana, A.; Massierer, C.; Moraes, C. H. de; Loose, E. B.; Neuls, G.; Gertz, L. Discursos e vozes por trás das COP-15 e COP-16. Anais do IX Encontro Nacional de Pesquisadores em Jornalismo, UFRJ, Rio de Janeiro, RJ, Brasil, 2011.

Gitlin, T. The Whole World is Watching: Mass Media in the Making and Unmaking of the New Left. Berkeley/Los Angeles: University of California Press, 1980.

Goffman, E. Frame analysis: an essay on the organization of experience. Boston: Northeastern University Press, 1986.
Hannigan, J. A. A Sociologia ambiental: a formação de uma perspectiva social. Lisboa: Instituto Piaget, 1995.

Indursky, F. A fala dos quartéis e as outras vozes. Campinas: Ed. da Unicamp, 1997.

Indursky, F. O sujeito e as feridas narcísicas dos linguistas. Gragoatá, Niterói, 5, 111-120, 2. sem. 1998.

IPCC - Painel Intergovernamental Sobre Mudança Climática, versão em português. Mudança do Clima 2007: a base das ciências físicas. Contribuição do Grupo de Trabalho I ao Quarto Relatório de Avaliação do Painel Intergovernamental sobre Mudança do Clima. Ecolatina, 2007. Disponível em: $<$ http://www.ipcc.ch/pdf/reports-nonUN-translations/ portuguese/ar4-wg1-spm.pdf $>$. Acesso em: 10. jul 2007.

Leff, E. Saber ambiental: sustentabilidade, racionalidade, complexidade, poder. Petrópolis: Vozes, 2001.

Leff, E. Aventuras da epistemologia ambiental: da articulação das ciências ao diálogo de saberes. Trad. Gloria Maria Vargas. Rio de Janeiro: Garamond, [2004] 2009.

Leff, E. Epistemologia ambiental. 5. ed. São Paulo: Cortez, [2000] 2010.

Maingueneau, D. A propósito do ethos. In: Motta, A. R.; Salgado, L. (Orgs.). Ethos discursivo. São Paulo: Contexto, 2008. p. 11-29.

Malin, M. Circulação das revistas em queda. Observatório da Imprensa, 749, 08 jun 2013. Disponível em: : <http:// observatoriodaimprensa.com.br/circo-da-noticia/circulacao-das-revistas-em-queda/>. Acesso em: jul. 2013

Mol, A. A modernização e a mudança dos modelos de controle de poluição industrial: a Teoria da Modernização Ecológica. In: Herculano, S.; Porto, M.; Freitas, C. Qualidade de vida e riscos ambientais. Niterói: Ed. UFF, 2000. p. 267-280.

Moraes, C. H. de. Rio+20 entre o clima e a economia: enquadramentos discursivos nas revistas brasileiras. Bauru, SP: Canal 6, 2016.

Moraes, C. H. de; Girardi, I. M. T. As cheias de 2010 na Revista Veja: a narração jornalística diante do "inesperado". Ação Midiática - Estudos em Comunicação, Sociedade e Cultura, 1, 1-25, 2012.

Olivieri, A. G. A teoria da modernização ecológica: uma avaliação crítica dos fundamentos teóricos. Brasília, Tese (Doutorado) - UnB, Departamento de Sociologia, 2009. 
Orlandi, E. P. As formas do silêncio: no movimento dos sentidos. 2. ed. Campinas, SP: Editora da Unicamp, 1993.

Orlandi, E. P. Interpretação: autoridade, leitura e efeitos do trabalho simbólico. 5. ed. Campinas: Pontes, [1996] 2007.

Orlandi, E. P. Análise de discurso: princípios e procedimentos. 9. ed. Campinas, SP: Pontes, [1990] 2010.

Pêcheux, M. Análise automática do discurso (AAD-69). Trad. Bethânia Mariani et al. In: Gadet, F.; Hak, T. Por uma análise automática do discurso: uma introdução à obra de Michel Pêcheux. 3. ed. Campinas: Ed. Unicamp, 1997.

Silveirinha, M. J. O lançamento da moeda europeia e os seus enquadramentos na imprensa. In: Anais Congresso
Brasileiro de Ciências da Comunicação. São Paulo: Intercom, 2005. CD-ROM.

Sorhuet, H. Periodismo ambiental, una de las claves para afrontar el cambio climático. In: Reyes, R. F. (Dir.); Mancinas-Cháves, R. (Coord.). Medios de comunicación y cambio climático. 1. ed. Sevilla: Fénix Editora, 2013. p. 135-146.

Traquina, N. Teorias do jornalismo: por que as notícias são como são. Florianópolis: Insular, 2005.

Tuchman, G. A objetividade como ritual estratégico: uma análise das noções de objetividade dos jornalistas [1978]. In: Traquina, N. (Org.). Jornalismo: questões, teorias e "estórias". Lisboa: Vega, 1993. 